\title{
Providing incentives for fishermen through rights-based co-management systems. An impact-assessment on Basque fisheries
}

\begin{abstract}
This research examines the social, economic and coercive incentives provided by fisheries management measures. Qualitative information was collected through interviews, and focus groups were organized to gather knowledge from regional stakeholders, to provide regional and European authorities with empirical evidence of the perceived legitimacy of current and future management measures under different co-management systems. Legitimacy greatly influences fishermen's behavior and therefore compliance. Qualitative and quantitative information are combined in an impact-assessment analysis to identify bio-socioeconomic impacts of different management measures on the fishing activity, under the current common fisheries policy, in the medium and long term. The results will help regional and European authorities define new management measures aimed at providing the right incentives to achieve the results. This paper demonstrates the necessity of introducing management measures that combine the various types of incentives mentioned.
\end{abstract}

Keywords: Common Fisheries Policy; Governance; Impact Assessment; Incentives; Comanagement.

\section{Introduction}

Many problems have remained unresolved since the previous reform of the Common Fisheries Policy (CFP) when considering the unsuccessful results of a wide range of management measures implemented [1], [2], [3] and [4]. The main question behind this study is the issue of why fisheries management has failed and which management measures fishermen feel most able to implement. This paper provides insights into the way new management measures should be formulated in order to be considered as real mechanisms for sustainable fishing activities within a consensual framework agreed to by all stakeholders. Sustainability implies setting and reaching multidisciplinary objectives able to address ecological, economic and social targets [5]. Moreover, institutional sustainability [6] is also needed to guarantee these objectives. Many fishermen and scientists claim that today's institutional model gives the wrong incentives, which is why they argue in favor of more closely integrating the industry into the management of the resources [7]. Knowledge of how the agents involved in the regulation perceive the measures has been undervalued when 
in fact it should be the cornerstone of successful management strategies [8]: a perception of increased legitimacy in fisheries management can lead to greater compliance [9]. Specifically, this paper identifies those incentives that new management measures could provide. Social, economic and coercive incentives play a key role in compliance and therefore the expected biosocioeconomic results. This research combines qualitative and quantitative techniques to analyze current and emerging management measures in the context of the new CFP (Regulation (EU) No 1380/2013), incentives for fishermen, and their behavioral responses to these. Moreover, it places the emphasis on management measure governance, i.e., how these incentives are achieved in local and regional contexts. One of the major recent trends in the fishing sector has been the increasing role of fishermen's organizations [10]. In the case of the Basque country (Spain), fisheries institutions play a key role in the day-to-day fishing activity. The pelagic fleet is organized under the umbrella of the cofradías, ancient institutions representing the interests of fishermen (boat owners and crew members), which centralize the trading of the fish caught by their members, among others. In turn, producer organizations (PO) group together industrial trawler owners. Cofradias now under the umbrella of the PO in order to access the powers provided to POs by the EU legal framework. Once the management measures have been well defined in terms of objectives, incentives, fishermen's perceptions, governance model, and other external factors, this paper examines the impact of these measures. The research simulates management measures and involves impact assessments (IA) based on this integrated framework in order to show the ecological, economic and social effects of the various scenarios selected following a dialogue between stakeholders and scientists. Finally, management measures are rated according to their biosocioeconomic effectiveness, economic efficiency, the fishermen's acceptance of the management measures, and their coherence according to the alreadyestablished management plans for the different stocks and fisheries. This approach enables us to recommend operational management measures that can create suitable incentives for tackling the main structural failings observed since the previous CFP reform. The work includes a specific regional case study involving Basque purse seiner and trawler fisheries under the umbrella of Spanish governance regulations. This case study was developed in the context of the European research project SOCIOEC $^{1}$ which is an interdisciplinary, Europewide project bringing together scientists from several fisheries sciences with industry partners and other key stakeholders.

\footnotetext{
${ }^{1}$ http://www.socioec.eu/
} 
The paper is structured as follows: Section 2 lays out a conceptual approach to developing impact assessment; Section 3 describes the Basque case study; Section 4 explains the methods; Section 5 presents the management measures to simulate and the external factors considered; Section 6 deals with the main results from the simulations; and finally, Section 7 presents the discussion and main conclusions.

\section{Links between science, stakeholders and managers: a framework for Impact}

\section{Assessment}

This research establishes a close link between science (IA of different management measures), stakeholders (potential incentives and the behavior of fishermen), and manager ( $\mathrm{s}$ including governance issues). Within this framework we have performed a qualitativequantitative IA in which the qualitative analysis provides arguments for understanding the failure or success of adopted management measures based on the creation of incentives and the behavior of the fishermen themselves. When management measures provide suitable incentives, successful results are usually attached to those measures [4]. Three types of incentives have traditionally been considered in fisheries: economic, coercive and social. The first are given when fishermen expect to increase their revenue from the activity. Coercive incentives may arise when European/national/local administration introduces a sanction for non-compliance. Finally, social incentives exist when fishermen have the opportunity to be involved in the decision-making process. In this sense, this paper analyses the impact of managing individual rights in a common-pool supported by cofradías and POs, implying that some stages of the management system are decentralized to POs. Thus, the social incentives structure is, in fact, related to the governance system adopted and, in particular, the type of co-management techniques [11] utilized by the stakeholders involved. The general objective of this paper is to provide empirical evidence of the need to introduce management measures that combine these different types of incentives to promote sustainable fishing [12]. The definition of multi-incentive management measures contributes to overcoming some of the main structural failings of the latest CFP, especially in relation to the lack of consensus about the prioritization of objectives, the short-term view, the top-down management structure that should be removed from the decision-making process, and the low level or even lack of compliance with the regulations. 


\section{Case study}

The Basque Country (northeastern Spain) is characterized by multi-fleet and multi-species fisheries fishing in different areas. This paper analyses the main fleets with base port at the Basque Country: the trawler and purse seiner fleets. Fisheries institutions are hugely important in the Basque Country: purse seiners are organized under the umbrella of the cofradias [13], and industrial trawler owners are grouped into POs. A revision of the comanagement system in Western Waters including a detailed description for the Basque fleet and fisheries can be found in Le Floc'h et al. [11]. The technical characteristics and some economic results are presented in Table 1. The trawler fleet comprises bottom otter trawlers and bottom pair trawlers [14] which operate in fisheries ${ }^{2}$ mainly managed through TAC (Total Allowable Catch) and TAE (Total Allowable Effort), enforced by various governmental agencies. Access rights were imposed on the Basque trawler fleet in 1981 ([15], [16]). Subsequently, in 1992, these rights became accumulable, and few years later, in 1997, the rights became transferable ${ }^{3}$ with limitations. Finally the current Individual Transferable Quota (ITQ) system ${ }^{4}$ was established in 2006 [17]. The Basque purse seiner fleet operates sequentially, distributing its activity across the mackerel, anchovy and tuna seasons, shifting fishing gear to pole and line (using live bait) and trolling in the tuna season. The main species targeted by the Basque purse-seiner fleet are regulated through TAC [18], although recently, individual fishing rights have been introduced to manage bluefin tuna (BFT) and mackerel.

The vessels of the trawler and purse seiner fleets are heterogeneous, for which reason the fleets have been split into segments. The trawler segments are otter trawler, (Sg1), pair trawler, $(\mathrm{Sg} 2)$, and longliners $(\mathrm{Sg} 3)$, with the main target species being hake $(\mathrm{Sp} 1)$, megrim (Sp2), mackerel (Sp3), horse mackerel (Sp4), and anglerfish (Sp5). For purse seiners, four segments are defined: pure purse seiners ( $\mathrm{Sg} 1)$, purse seiners and trolling ( $\mathrm{Sg} 2)$, purse seiners and live bait with high BFT catchability ( $\mathrm{Sg} 3)$ and purse seiners and live bait with low BFT catchability ( $\mathrm{Sg} 4)$ representing, over the whole Basque purse seiner fleet size, the $40 \%, 19 \%$, $5 \%$ and 36\% respectively. Their main target species are anchovy (Sp1), horse mackerel (Sp2), mackerel (Sp3), sardine (Sp4), albacore (Sp5), and BFT (Sp6).

\section{[Insert Table 1]}

\footnotetext{
${ }^{2}$ A fishery is a group of vessel voyages targeting the same (assemblage of) species and/or stocks, using similar gear, during the same period of the year and within the same area (study group on the development of fisherybased forecasts, ICES, 2003). The location does involve the definition of a fishery (Prellezo et al, 2009).

${ }^{3}$ Royal Decree 1915/1997.

${ }^{4}$ Order APA/3773/2006.
} 


\section{Management measures impact assessment: method and data}

The IA method (EU, 2009), which follows the conceptual approach introduced in section 2, was developed in the three generic stages displayed in Figure 1.

Stage one - consists of a qualitative assessment in which semi-structured face-to-face interviews with representatives of the Basque fishermen were conducted in order to analyze fisheries governance issues. In addition, focus groups were organized with scientists, fishermen, and other stakeholders (Non-governmental organizations) to examine fisheries management measures and, more importantly, the behavior of fishermen, particularly regarding compliance. ${ }^{5}$ The main objectives and the indicators used in the assessment were also discussed in these meetings.

Stage two - the simulation stage comprises a quantitative assessment using the FishRent model to evaluate the bioeconomic performance of the fleets over a period of 25 years. FishRent is a multifleet and multispecies model composed of six modules (see references[19, 20] for detailed information about the model: a biological module (stock-growth relation and biomass function), an economic module (revenues, costs, cash flow, etc.), an interface module (production function, discards and landings), a market module (price of fish and fuel price), a behavior module (fleet size, effort and investment) and finally, a policy module that determines the level of landings and/or the effort involved. FishRent model includes within the catch production function the catch developed by "other segments" apart from the local purse seine and trawler fisheries in which the paper focuses on. This is the way of introducing the potential effect of other fisheries.

A set of scenarios have been identified for which medium to long term simulations have been run. The scenario approach takes into account the baseline, the status quo, and potential management alternatives for which different endogenous and exogenous variables are considered. Endogenous variables are generally simulated by the model through dynamic equations (effort, investment functions, etc.), while exogenous variables are associated with external factors.

Stage three - the rating stage establishes a management measure rating based on acceptability, effectiveness, efficiency and coherence. Acceptability analyses the

\footnotetext{
${ }^{5}$ In particular, more than 50 people from inshore sector took part in the focus groups, which represent $40 \%$ of the total inshore fishing guilds, the $100 \%$ of fishermen representatives at the Basque Country, around 20 scientific from UK, France and the Basque Country and, two members of non-governmental organizations.
} 
stakeholders' willingness to accept and comply with regulatory management, namely whether the sector perceives a particular management measure to be effective, fair and easy to apply. Effectiveness measures the extent to which the specific objectives (biological, economic and social) are achieved. Efficiency is related to the level of resources employed and the results achieved. Finally, coherence refers to the extent to which management options are consistent with the overarching objectives of the CFP and the operational objectives as defined in the management options. Acceptability and coherence are assessed during the qualitative stage. The effectiveness is evaluated using the value of the indicators included in FishRent pertaining to the three dimensions (biological, economic and social). The indicators used are: fishing mortality $\left(\mathrm{I}_{\mathrm{B}}\right)$, economic viability $\left(\mathrm{I}_{\mathrm{Ec} 1}\right)$, sector attractiveness through return on fixed tangible assets (RoFTA) ( $\left.\mathrm{I}_{\mathrm{Ec} 2}\right)$ and social stability $\left(\mathrm{I}_{\mathrm{s}}\right)$ through average crew remuneration. These indicators can be expressed as:

$$
\begin{gathered}
I_{B}=\frac{\text { Catches }}{\text { Biomass }} \\
I_{E c 1}=\frac{\text { Profit }}{\text { Revenue }} \\
I_{E c 2}=\frac{\text { Profit } \text { year }_{\text {asset value }}}{\text { Fixed tangible capital asere year }_{n}}=1, \ldots, n \\
I_{S}=\frac{\text { Total remuneration }}{\text { Employment }}
\end{gathered}
$$

In addition, two reference points are considered: the limit referent point (LRP) and target reference point $\left(\mathrm{TRP}^{6}\right)$ [21]. The LRP should not be exceeded due to possible undesirable consequences and, TRP should be reached to maximize benefits from the fishery. Once TRP and/or LRP, as well as the indicators, have been assessed, the effectiveness is evaluated by constructing a synthetic index that compares the indicators in relation to the reference points, taking into account the starting point of the simulation (current situation). Specifically, the target effectiveness index $\left(\mathrm{TEI}_{\mathrm{I}}\right)$ is defined by the following ratio where curr is the current situation:

$$
T E I_{I i}=\frac{I_{i}-I_{i, \text { curr }}}{T R P_{i}-I_{i, \text { curr }}} ; \quad \text { where } i=B, E C_{1}, E C_{2} \text { and } S
$$

\footnotetext{
${ }^{6}$ The biologic TRP is estimated as the Fmsy (Fishing mortality consistent with achieving Maximum Sustainable Yield (MSY), (see ICES Advice, Section 1.2)) multiplied by the sum of the all TAC share of all sub-segments of the studied fleets. The economic TRP is estimated as the initial year's indicator plus an increase of $15 \%$. The social TRP is the average salary of the inshore fleet of the Basque country (22 $000 € /$ year).
} 
When TEI is equal to 1 , the objective is achieved $^{7}$. Finally, a cost-benefit analysis is performed to assess the efficiency through future costs, and the revenue net present value (NPV) indicator is evaluated.

\section{[Insert Figure 1]}

\section{Management measures and external factors: IA applied to the case study Basque purse seiners}

The status quo involves a traditional top-down regulation system based on TAC. The northeast Atlantic and Mediterranean BFT quota is first allocated by ICCAT to the EU and then to Spain and other member states. The alternative scenario is the introduction of individual quotas (IQ) for BFT, which originates from a previously established technological share. Technological shares allow the Spanish government to impose a stricter control on landings in order to prevent the national quota being exceeded [10]. Each share is established on the basis of the fishing activity, expressed as historical catches (60\%) and socioeconomic dependency criteria (40\%) (Order ARM/1244/2008). Shares of the national quota were estimated for vessels and fishing traps, each being award individual quotas [10]. According to the regulations in force (Order AAA/642/2013) these IQ can be pooled. Alternative scenarios refer to the implementation of the IQ managed under a common pool framework. Within this alternative, two external factors have been simulated: EFO - IQ could be traded (10 euro/kg) between the diverse Spanish fishing technologies for two years of every five, e.g., from Cantabrian purse seiners to Mediterranean tuna farm purse seiners. EF 1 implies a definitive transfer of the IQ, which considers the sale of the IQ for 3 consecutive years, only among same fishing technologies and, the subsequent definitive loss of the quota. The reallocation of effort toward other species was simulated when introducing $E F O$ and $E F 1$, the effort being allocated to albacore since this species and BFT are both caught using live bait and in the same season. The reallocation of effort has been introduced in the model through an increase of ALB catches (it is assumed to be $5 \%$ by year) plus an increase of variable costs (it is assumed to be $1 \%$ ) because ALB it is caught farther away than BFT. These data are based on fishers' empirical knowledge and historical data.

\footnotetext{
${ }^{7}$ If TEI is lower than 0 the results of a given scenario are worse or equal to the current situation and worse than TRP. When TEI is between 0 and 1, the result deriving from a given scenario is better than the current situation even if the target has not already been achieved. When an indicator is compared to LRP, the limit level and the current situation are compared in two steps; the first step compares the indicator value with the LRP and the indicator value with the current situation; the second step involves a synthesis of the previous comparisons. The comparison between the indicator value and the LRP produce the LEI indicator. When the result is higher than the LRP, LEI is equal to 1; when the result is worse than LRP, then LEI is equal to -1 ; and when LEI is 0 the result of the new management option is better than the current situation, but the LRP has not yet been exceeded.
} 


\section{Basque trawlers}

In the status quo, fisheries are managed on the basis of a TAC share allocated to Spain plus an ITQ system. From 2006 onwards, new provisions on the transferability of rights propitiated the emergence of a form of ITQ system not based on open markets for trading of rights, with the transferability being restricted to vessels belonging to the offshore demersal fleet. The ITQ system was temporarily implemented in 2006 and made permanent in 2008 [10].

The alternative in this case was the introduction of the landing obligation (LO) policy, imposed by the most recent CFP, which implies that all catches of species subject to catch limits shall be brought in and retained on board. The alternative considers three external factors: $E F O$ allows the number of vessels to be changed, closely linked to the optimal economic long-term performance; $E F 1$ involves scrapping subsidies, given that eliminating these is one of the main problems in the sector that puts pressure on less-efficient vessels not to leave due to the high cost; $E F 2$ introduces TAC share allocation changes. According to the fishermen's perception, the quotas for Basque trawlers are too low and the presence of foreign fish in the regional markets may bring prices down for some species, particularly hake. Table 2 shows the scenario matrix considering different combinations of measures and external factors.

\section{[Insert Table 2]}

\section{Impact Assessment results}

\section{Basque purse seiners}

The economic results under the alternative scenarios are slightly better than for the status quo in the medium term, with an increased Net Present Value of the Gross Value Added (NPV of the GVA) of $0.9 \%$. However, when moving into the long term the NPV of GVA and profit, $0.3 \%$ and $23 \%$, respectively, are lower for the alternative scenario, the number of vessels being $14 \%$ higher than in the status quo. This result is perhaps surprising as it is generally accepted that the introduction of individual rights assists in reducing fleet overcapitalization [22] and in improving economic benefit [23]. However, in the alternative scenario, the introduction of IQ is accompanied by common pooling managed under the umbrella of the cofradías. For the Basque purse seiners, common-pooling implicitly means a homogeneous distribution of the BFT quota among all vessels implying, firstly, easier joint management of the resources, and secondly, greater bargaining power when selling quotas $(E F 0)$. According 
to the sector, all these social benefits offset any potential profit losses. Currently, the Basque purse seiner fleet temporarily transfers its quota to the Mediterranean farm companies. The price per kilogram of BFT quota $(10-11$ euro/kg) is high compared to the price of captured BFT (5.6 euro/kg). Thus, the EFO improves the alternative scenario's economic results, making them even better than those of the status quo in the long term. EF1 goes against the sustainability of the sector (NPV of the GVA and profit decrease 14\% and 40\%). This result is in line with the perception of the stakeholders, who do not want to permanently lose the IQ. It is preferable to never sell IQs rather than sell them three consecutive years.

Notice that not all the segments are affected equally by external factors within the alternative scenario. In the status quo, the yearly GVA of $\mathrm{Sg} 3$ is always higher than in alternative, while the opposite is true with Sg4 ([Insert Figure 2). The homogeneous redistribution of the BFT rent that occurs within the alternative implies that the $\mathrm{Sg} 3$ yields part of its BFT rent to $\mathrm{Sg} 4$.

\section{[Insert Figure 2]}

In terms of the NPV of the profit, Sg4 benefits from the common pooling of the IQ, with positive results for the alternative scenario while in the status quo this value is negative. The contrary occurs for $\mathrm{Sg} 4$, where the results in the alternative scenario are lower than for the status quo. Comparing the status quo and the most likely scenario, i.e., EFO within the alternative scenario, [Insert Figure 3 shows strong differences between the biological results in the medium and long term. The catchable biomass of the vast majority of species is the same or slightly higher in the medium term for the alternative scenario given $E F O$ but, the contrary occurs in the long term. The main difference is in BFT (Sp6), whose biomass in the 13 first years of the projection is higher when considering EFO in the alternative scenario, but after this point, the biomass of the status quo is higher. This variation could be due to the number of vessels operating in the fishery, as beyond year 13 of the projection, the number of vessels working in the fishery is higher under the alternative scenario given EFO ([Insert Figure 4).

[Insert Figure 3]

[Insert Figure 4] 


\section{Basque trawlers}

The alternative scenario implies an important adjustment of the fishing activity of the Basque trawlers in relation to the status quo (under which the sector achieves good bioeconomic results). The total NPV of the GVA at 15 and 25 years will be reduced around $45 \%$. When considering the NPV of the profits at 15 and 25 years this percentage becomes reduced by around $88 \%$, which could compromise the future fishing activity. However, the outcome depends on the different trawler segments: the evolution of $\mathrm{Sg} 2$ will be the worst, while the rest of the segments will remain more or less stable. In particular, Sg2 will have the capacity to increase its number of vessels by up to $50 \%$ in the long term. For the biological dimension, the catchable biomass under the alternative scenario is higher than for the status quo, for all species in both the short and medium term. However, the catchable biomass reaches a similar level in the long term (after 25 years) for all species except Sp1 and Sp5, whose catchable biomass is much higher within the alternative scenario ([Insert Figure 5).

EF $O$ favors better economic results. The optimal economic outcome is produced after the disinvestment of five vessels. EF 1 (alternative) represents is key in terms of the economic sustainability of the fishery over the long term because the elimination of scrapping subsidies will prevent fishermen leaving the activity, generating an additional reduction around $2 \%$ of the NPV of the GVA at both 15 and 25 years. The negative impact of EF1 on profits is very important with the NPV of benefits at 25 and 15 years becoming negative and close to zero, respectively. EF 2 under the alternative scenario involves an increase of the TAC allocated to Spain, something which has been demanded by the sector since the last decade. When increasing the hake TAC by $10 \%$, the NPV of profits at 25 years becomes positive (although close to zero) even without taking into account a potential positive impact of this change on first-sale prices (due to the possible import reductions). The results on the number of vessels and GVA evolution are displayed in [Insert Figure 6 and [Insert Figure 7.

[Insert Figure 5]

[Insert Figure 6]

[Insert Figure 7] 
Rating stage results for Basque purse seiners and trawlers:

The results according to criteria are summarized in 
Table 3. The acceptability of the alternative management is a fact given the outputs obtained from the qualitative stage. There are trade-offs for Basque purse seiners given that some fishermen could lose certain revenues due to the establishment of a BFT common quota pool, but at the same time those fishermen could obtain social benefits thanks to the power of the POs to manage the global quota. In this sense, the fishing sector management is developing its efforts to also extend the IQs for the other target species. The opposite happens with the introduction of LOs, mostly affecting the trawler sector. The sector considers the measure to be unnecessary and inappropriate because the policy makers have not taken into account the specific characteristics of the Basque demersal fisheries. Thus, it is expected not to produce the right economic incentives [24].

Effectiveness. In the case of the Basque purse seiners, in the medium term the alternative scenario with $E F O$ provides the best effectiveness index values for almost all dimensions but in the long term, the status quo achieves better index values for the majority of dimensions. It is worth mentioning that the social index is only related to fishermen's salaries, not the amount of employment. In the efficiency evaluation, the NPV of the profit is positive for all scenarios, and the most efficient management measure, for any time horizon, is the alternative with $E F O$.

It seems to be clear that the management model based on ITQs (status quo) leads the Basque trawler segment to achieve a good LEI and TEI index for all economic and social indicators in the long term. However, these indexes show a negative change when analyzing the application of LOs (alternative), becoming even worse when introducing $E F 1$, related to the lack of scrapping subsidies.

The trawler fishing activity is considered to be efficient given the positive results attached to the NPV of the GVA and profits, except when applying the LO policy under a framework in which scrapping subsidies are removed (alternative affected by EF1) where the NPV of profits even become negative.

Coherence. One of the main objectives included in the BFT long-term management plan was improving compliance with TAC and mitigating the impacts of overcapacity [25]. Moving away from a traditional top-down to co-management framework (alternative) usually improves compliance [10]. Regarding the overcapacity objective, in the long term the alternative scenario results in the highest number vessels in the Basque purse seiner fleet, especially when considering $E F O$.

[Insert Table 3] 


\section{Discussion and conclusions}

Fishery managers seek to obtain good results when applying management measures, but empirical evidence shows that the applied management measures do not meet the expected results in all cases. The specific characteristics of a fishery, the incentives created, external factors influencing the activity, and even the time scale for achieving the objectives all play a key role in whether a management measure is successful or not. The specific characteristics of the Basque purse seiner and trawler fleets are highlighted in order to assess the various management measures in force under different co-management strategies and external factors. The introduction of a common-pool IQ for managing BFT, in contrast to the previous TAC system, produces sufficient social gains to guarantee aggregate or collective economic benefits, being considered by the Basque purse seiner sector as a successful measure. The IQ system creates economic incentives [23] but the common-pool itself implies a redistribution of the rent, favoring those segments that previously had a low BFT catchability. Socioeconomic gains should be understood in the sense that POs collectively conduct quota trading, thus getting better prices. The Basque purse seiner sector feels that it is better for all vessels to work together for all species. The potential benefit of pooling is usually described in terms of reduced risk of income fluctuation and net damages [26] among other aspects. The sector's representative considers that in a scenario involving a larger BFT quota the sector's priority should be to fish, rather than transfer the rights, even though transference could provide the best results in terms of effectiveness and efficiency. However, the decision depends on the context, if the price differential between the IQ market and the price per captured kilogram is too high, or if fuel prices become excessive, they may consider transferring their quota.

This semi-private management system, referred to as co-management by partnership, is able to combine social and collective economic incentives thanks to the involvement of POs in the decision-making process, making it easier for the fishermen to accept the management measures. However, depending on the time scale of the impact assessment, the management option could lead to either successful or unsuccessful results. In the medium term, individual quotas managed in a common pool with a transferability option is the most suitable management option for the BFT fishery, but in the long term, this result is not necessarily maintained.

The analysis of the institutional relationship types is of utmost interest for understanding the success of the measures. In 2014, the successful medium-term quota-based system was 
transferred from the BFT fishery to the mackerel fishery (Order AAA/417/2014), also exploited by Basque purse seiners, as well as other Basque fleets.

The offshore fishing sector agreed to manage the activity through an ITQ system. This measure entails a determined distribution of rights among the vessels, which also affords them the possibility of transferring these rights. The POs contribute to managing the readjustment of rights, in such a way that it results in good economic performance for the offshore sector. The sector under this framework (status quo) produces good socioeconomic results but claims that the roots of the sector's problem can be found in the initial allocation of the national share by the European Commission. The Basque trawler fishermen's representative cites the low TAC level as the main problem attached to the sector, and this is the reason why traditionally the sector has asked to break down the relative stability principle or increase the TAC level, although they also recognize the impossibility, or at least enormous difficulty, of changing this situation. This external factor, the TAC level, is specifically considered as a way to allow recovery when applying LOs, which will seriously affect the effectiveness and efficiency of the trawler segment in relation to the status quo.

Applying LOs will cause economic incentives to disappear if they are not developed under a context of co-management. The legitimacy and effectiveness of the LO policy is not only vital for increasing the influence of actors from civil society, but also the participation of resource users [24]. Otherwise, resistance become too high, and regulation becomes more of a symbol than a truly useful tool unless coercive incentives are applied. De Vos and van Tatenhove [24] explain in detail that one of the reasons for the Basque sector not accepting the application of this measure is the fact it was introduced through a traditional top-down management model, in contrast to a more participatory process. Thus, establishing LOs in a participatory management model is the only way to gain compliance with the acceptability criteria, although socioeconomic incentives may disappear, leading to decreased effectiveness and efficiency.

Other past experiences illustrate the non-acceptability of implementing IQ via the traditional top-down system. Le Floc'h et al. [11] gives a detailed description of the allocation of proportions of Basque mackerel quotas to different fishing techniques. In this case, the national regulation was implemented in 2010 (Order ARM/271/2010) with the aim of distributing the Spanish catch quota by gear. Landing limits have been considered for the mackerel fishery in recent years. In 2009, within a top-down hierarchical management structure, daily limits were introduced by the Spanish administration (Order ARM/2091/2008) with the expectation of an economic incentive (daily price increases). However, the results 
were unsuccessful in terms of acceptability, effectiveness, coherence and efficiency [27, 28]. The fishermen did not accept the measures introduced under a traditional top-down management mainly due to (i) the fishermen's expert knowledge on good mackerel stock status, (ii) the high level of competition between the different fleets for the mackerel stock, (iii) the seasonal character of the fishery, and (iv) low first-sale prices. The dissipation of economic incentives together with an absolute lack of social incentives motivated noncompliant behavior, pushing the Spanish administration to introduce coercive incentives, through reinforced controls at ports, as well as sanctions (deduction of quota) for overfishing mackerel (Regulation (EU) No 185/2013). Thus, compliance was attained through coercive management, although this also involved an excessive use of public funds and did not assure the effectiveness and efficiency of the activity. After the failure of these mackerel fishery management measures, one possible path to success remaining for the fishing sector is a move towards co-management with a common pool model. In 2014, an IQ for mackerel was implemented, but this is yet to be analyzed. Greater understanding of the incentives, external factors and institutional issues constitutes a good starting point in the formulation of new and successful management measures.

\section{Acknowledgements}

This work was funded by the EU 7FP Project SOCIOEC (Socioeconomic effects of management measures of the Common Fisheries Policy Grant agreement No.289192) and by the Department of Agriculture and Fisheries of the Basque Country. This paper is contribution no.xxx from AZTI (Marine Research Division).

\section{References}

1. Da Rocha, J.-M., S. Cerviño, and S. Villasante, The Common Fisheries Policy: An enforcement problem. Marine Policy, 2012. 36(6): p. 1309-1314.

2. Coelho, M.F., Rights Based Management and the Reform of the Common Fisheries Policy: The Debate. International Journal of Latest Trend in Finance and Economic Sciences, 2011. Vol 1.

3. Khalilian, S., et al., Designed for failure: A critique of the Common Fisheries Policy of the European Union. Marine Policy, 2010. 34(6): p. 1178-1182.

4. Österblom, H., et al., Incentives, social-ecological feedbacks and European fisheries. Marine Policy, 2011. 35(5): p. 568-574.

5. Garcia, S.M., D.J. Staples, and J. Chesson, The FAO guidelines for the development and use of indicators for sustainable development of marine capture fisheries and an Australian example of their application. Ocean \& Coastal Management, 2000. 43(7): p. 537-556.

6. Charles, A.T., Sustainable fishery systems2008: John Wiley \& Sons. 
7. Gutierrez, N.L., R. Hilborn, and O. Defeo, Leadership, social capital and incentives promote successful fisheries. Nature, 2011. 470(7334): p. 386-389.

8. Garza-Gil, M.D., et al., Perceptions on incentives for compliance with regulation. The case of Spanish fishermen in the Atlantic. Fisheries Research, 2015. 170: p. 30-38.

9. Kraak, S.B.M., D.G. Reid, and E.A. Codling, Exploring the RTI (real-time incentive) tariff-based approach to single-species fisheries management. Fisheries Research, 2014. 155: p. 90-102.

10. Aranda, M. and A. Murillas, Allocation of fishing possibilities, incentives and outcomes: Insights from Basque fishermen's organisations in Spain. Marine Policy, 2015. 61: p. 171-178.

11. Le Floc'h, P., et al., The regional management of fisheries in European Western Waters. Marine Policy, 2015. 51: p. 375-384.

12. Grafton, R.Q., et al., Incentive-based approaches to sustainable fisheries. Canadian Journal of Fisheries and Aquatic Sciences, 2006. 63(3): p. 699-710.

13. Kepa Astorkiza, I.d.V.E., Inmaculada Astorkiza Ikazuriaga, Fisheries Policy and the "Cofradias" in the Basque Country: The Case of Albacore and Anchovy. Documento de Trabajo 9809. Departamento de Economía. Universidad Pública de Navarra, 1998.

14. Iriondo, A., Prellezo, R., Santurtún, M., García, D., Quincoces, I. Mugerza, E, A multivariate approach for metier definition: A case study of Basque Country trawlers Revista de Investigación Marina, 2010. 17(6): p. 139-148.

15. Prellezo, R., et al., A qualitative and quantitative analysis of selection of fishing area by Basque trawlers. Fisheries Research, 2009. 97(1): p. 24-31.

16. Laxe, F.G., Transferability of fishing rights: The Spanish case. Marine Policy, 2006. 30(4): p. 379-388.

17. Prellezo, R., La Evolución de la Flota de Altura al Fresco en el Contexto del Marco Legislativo Español. Revista de Investigación Marina, 2010. 17(3): p. 21-27.

18. Andrés, M. and R. Prellezo, Measuring the adaptability of fleet segments to a fishing ban : the case of the Bay of Biscay anchovy fishery. Aquatic Living Resources, 2012. 25(03): p. 205-214.

19. Salz, P., et al., Study on the remuneration of spawning stock biomass. Final Report, Framian, 2010.

20. Salz, P., Buisman, E., Soma, K., Hans, F., Acadia, P., and Prellezo, R., FISHRENT, Bioeconomic simulantion and optimisation model for fisheries. LEI Report 2011-024, May 2011.

21. Caddy, J.F. and R. Mahon, Reference points for fisheries management. Vol. 374. 1995: Food and Agriculture Organization of the United Nations Rome.

22. Emery, T.J., et al., Are input controls required in individual transferable quota fisheries to address ecosystem based fisheries management objectives? Marine Policy, 2012. 36(1): p. 122-131.

23. Yagi, N., et al., Applicability of Individual Transferable Quotas (ITQs) in Japanese fisheries: A comparison of rights-based fisheries management in Iceland, Japan, and United States. Marine Policy, 2012. 36(1): p. 241-245.

24. de Vos, B.I. and J.P.M. van Tatenhove, Trust relationships between fishers and government: New challenges for the co-management arrangements in the Dutch flatfish industry. Marine Policy, 2011. 35(2): p. 218-225.

25. ICCAT, Recommendation by ICCAT to establish a multi-annual plan for bluefin tuna in the Easterns Atlantic and Mediterranean. www.iccat.int, 2006. 06-05 BFT.

26. Zhou, R. and K. Segerson. Individual vs. Collective Quotas in Fisheries Management: Efficiency and Distributional Impacts. in 2014 Annual Meeting, July 27-29, 2014, Minneapolis, Minnesota. 2014. Agricultural and Applied Economics Association. 
27. García, J., J. Arteche, and A. Murillas, Fractional integration analysis and its implications on profitability: the case of the mackerel market in the Basque Country. Fisheries Research, 2010. 106(3): p. 420-429.

28. García-Enríquez, J., et al., Spatial Integration in the Spanish Mackerel Market. Journal of Agricultural Economics, 2014. 65(1): p. 234-256. 


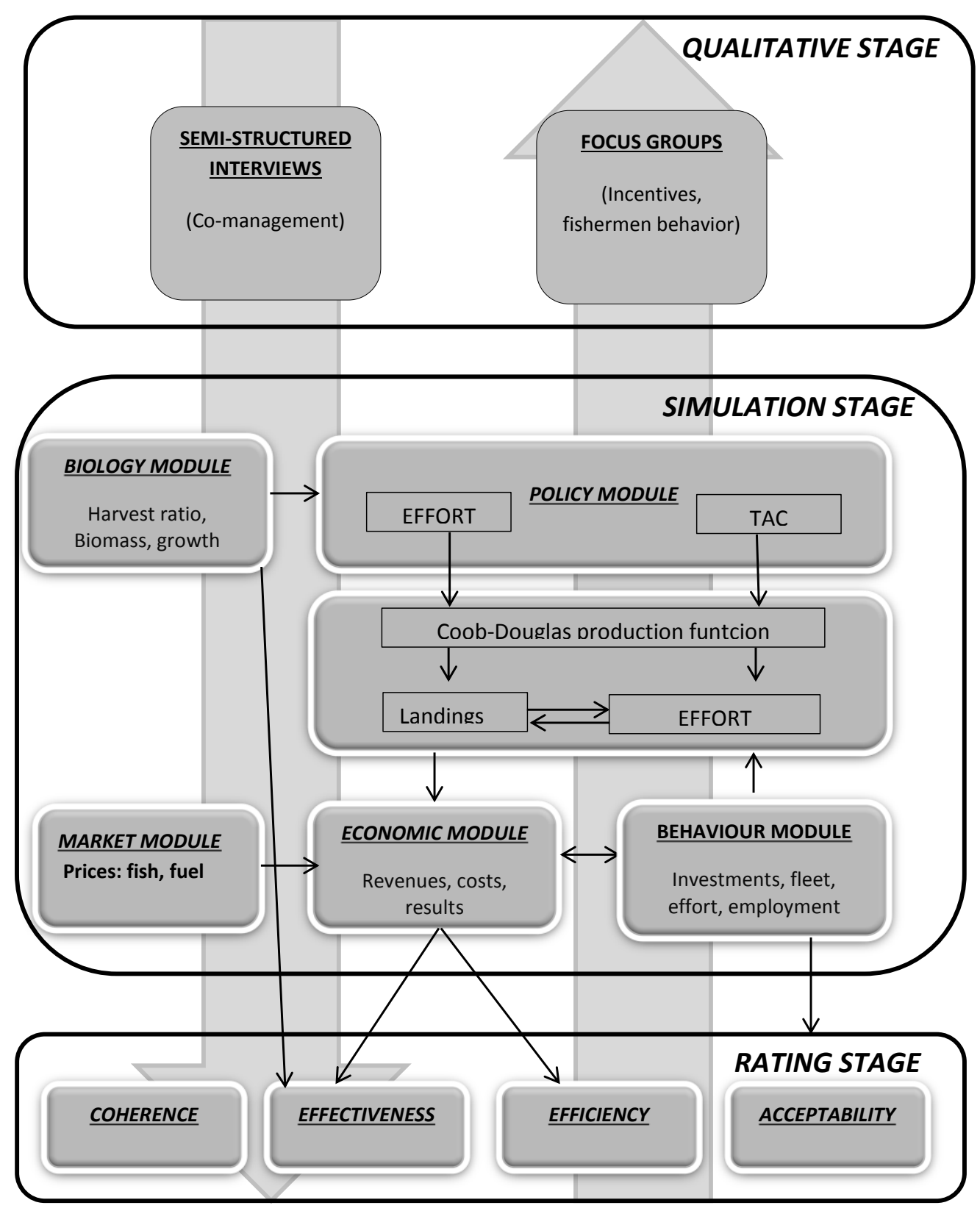

Figure 1 


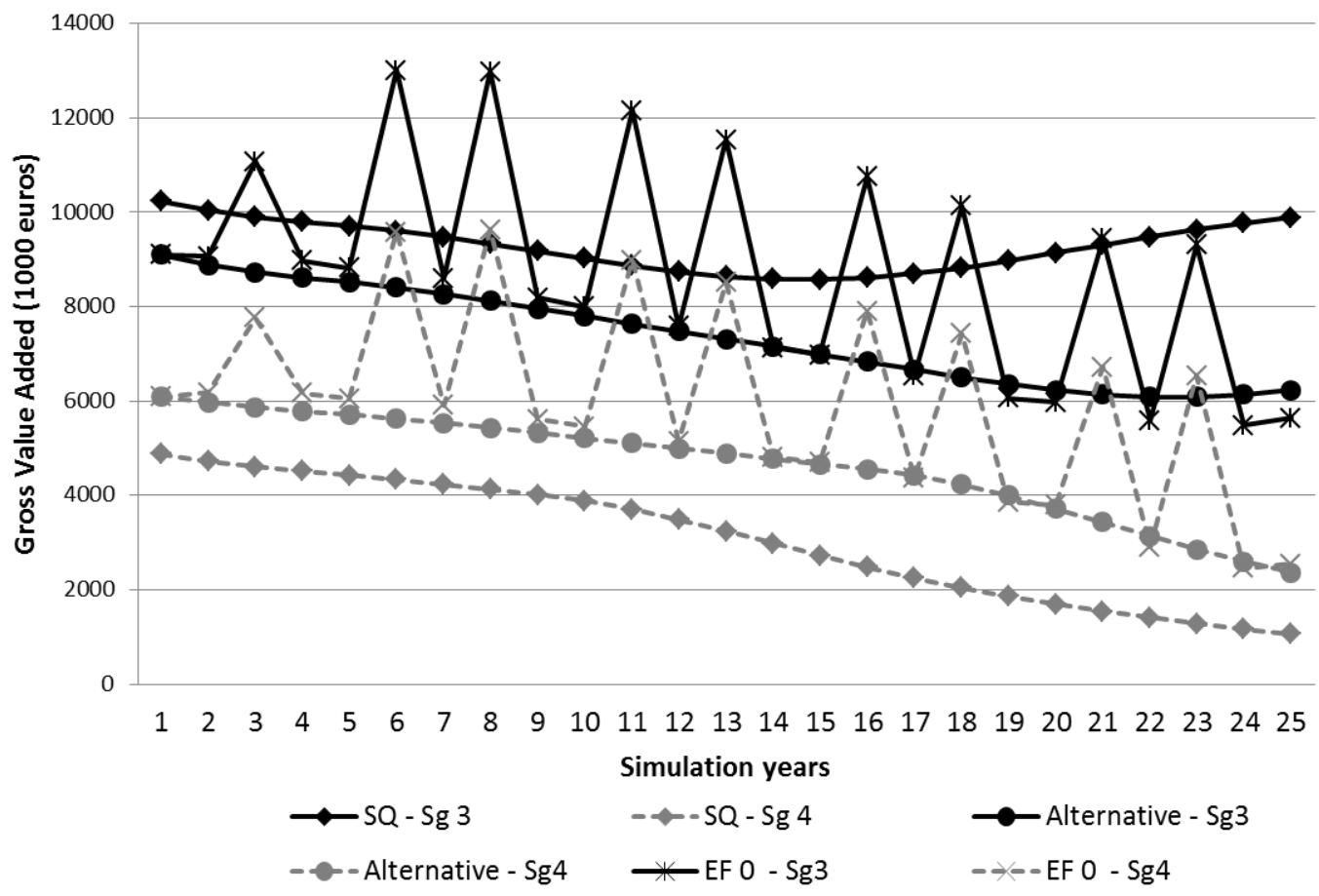

Figure 8 


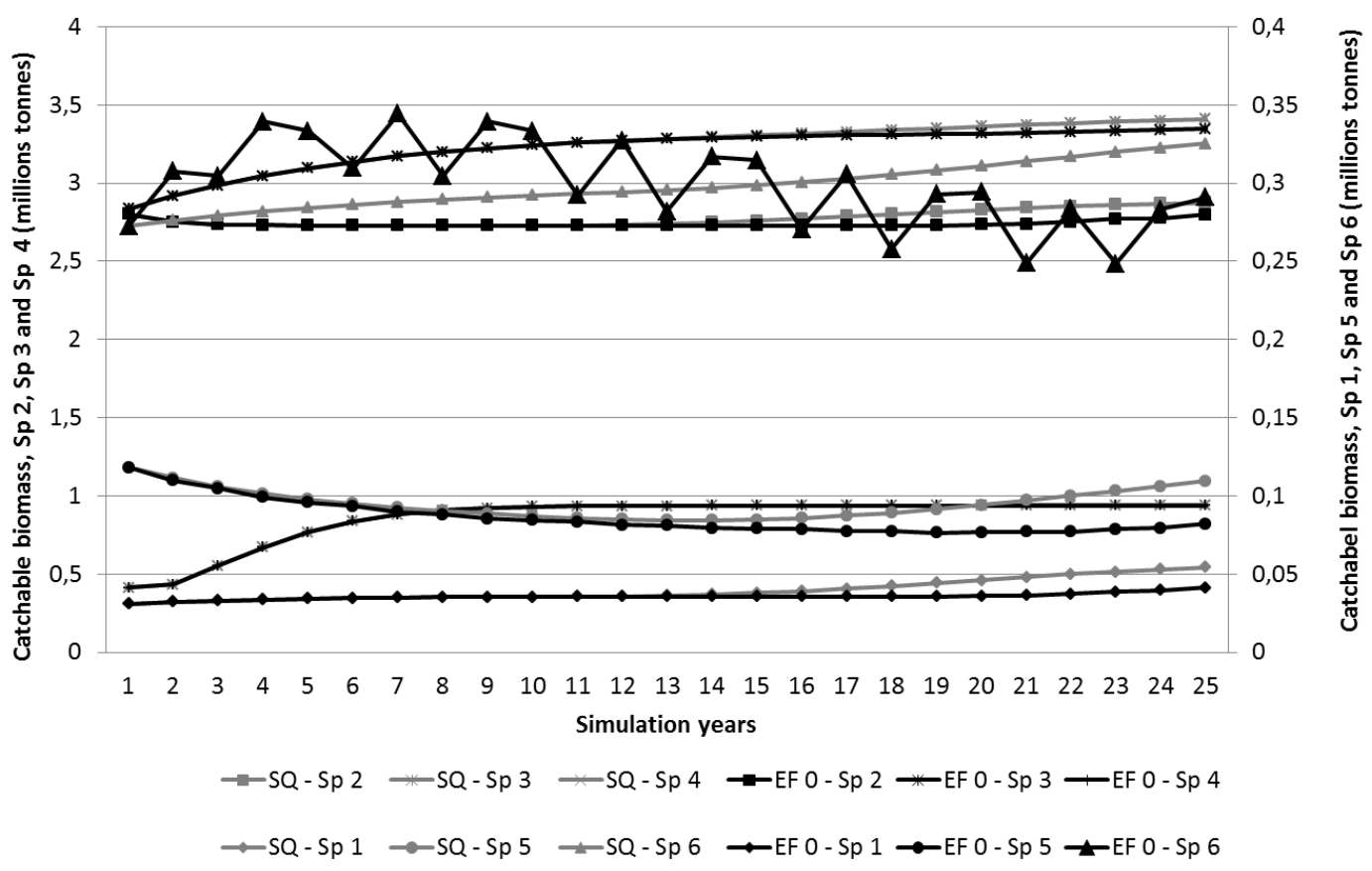

Figure 9 


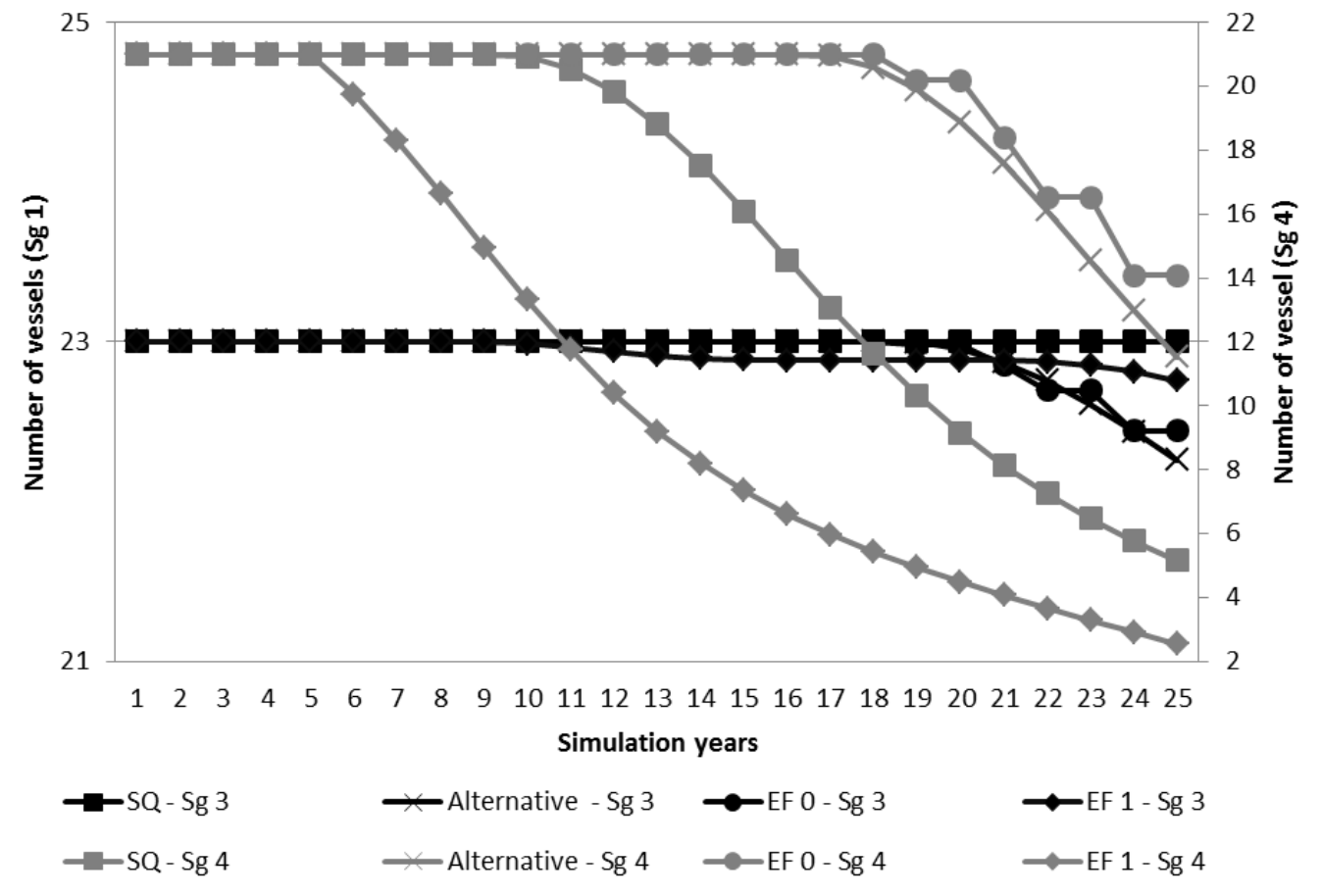

Figure 10 


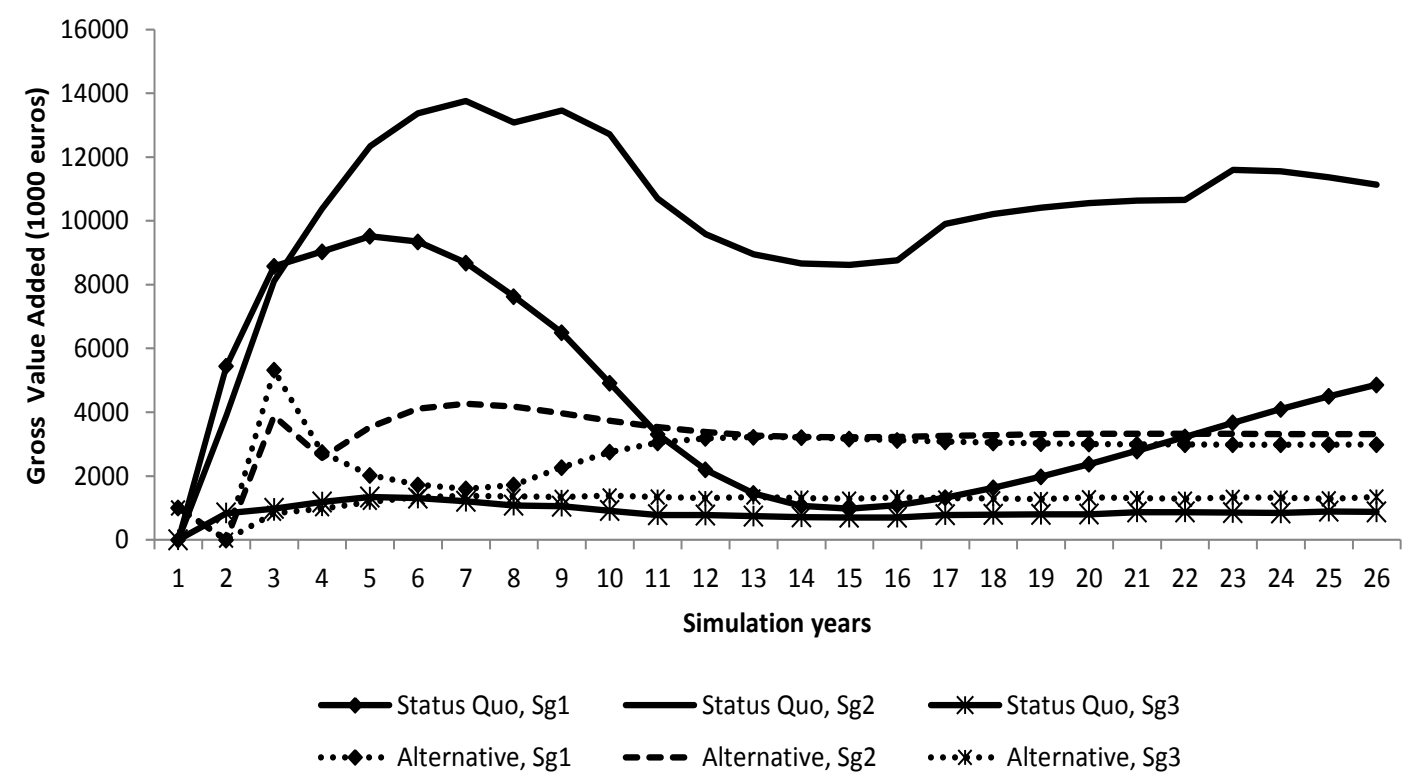

Figure 11. 


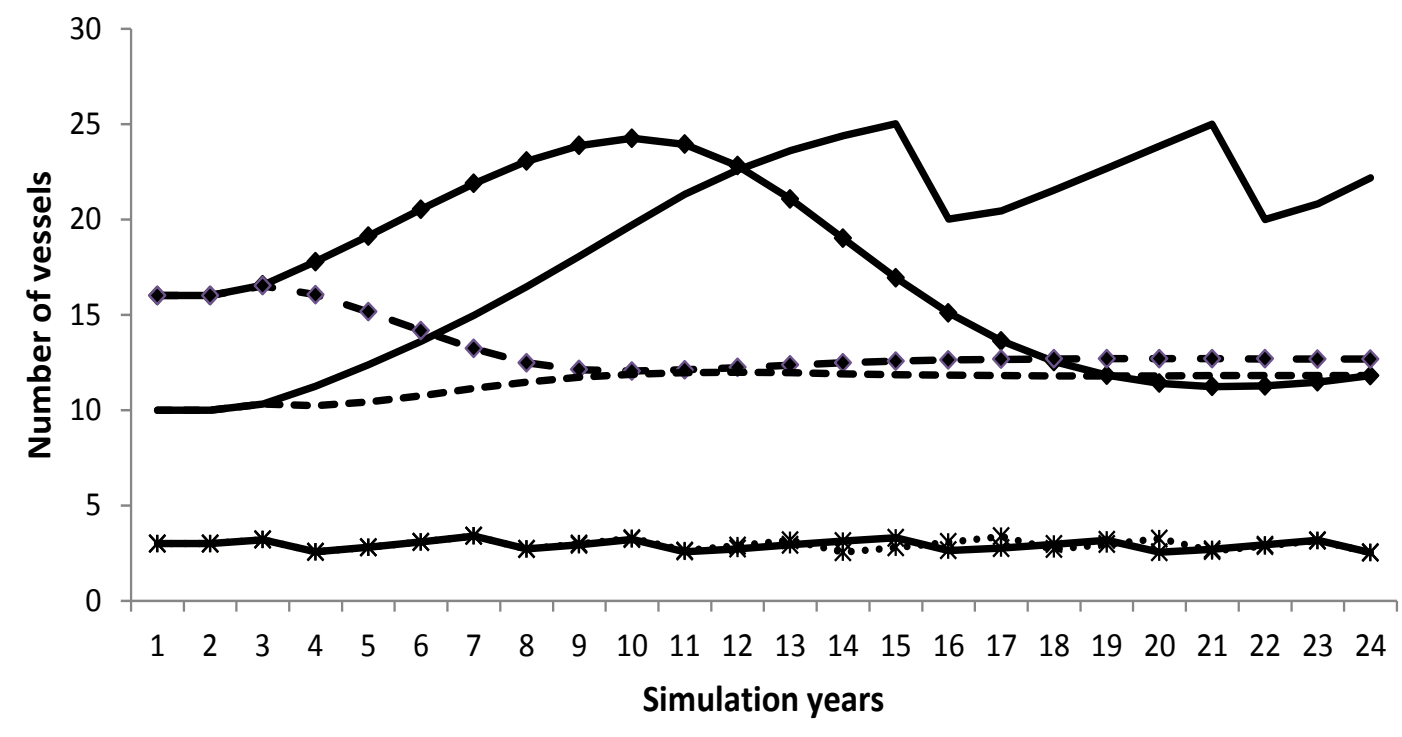

$\begin{array}{lll}- \text { Status Quo, Sg1 } & \text { Status Quo, Sg2 } & -* \text { Status Quo, Sg3 } \\ - \text { Alternative, Sg1 } & \ldots \text { Alternative, Sg2 } & \cdots * \text { Alternative, Sg3 }\end{array}$

Figure 12. 


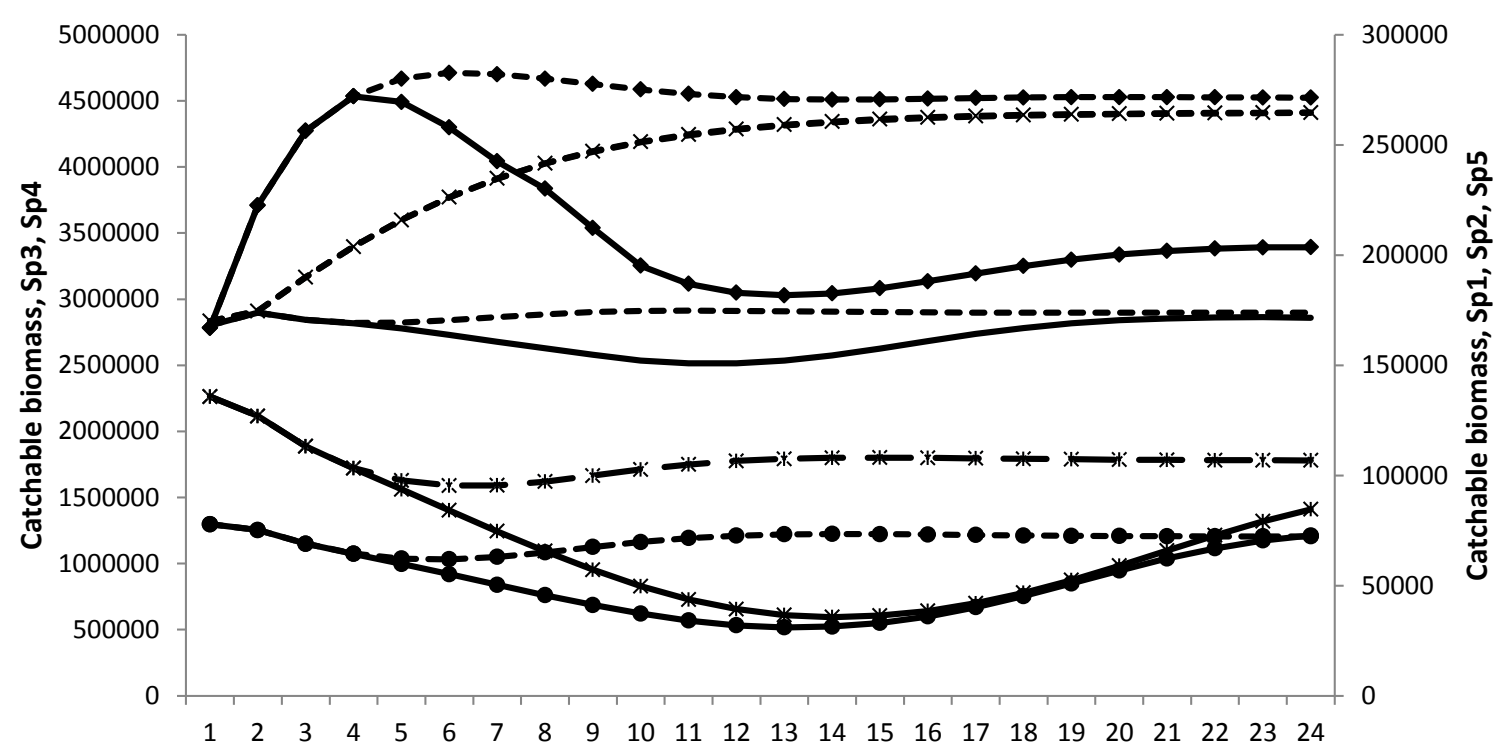

Simulation number of years

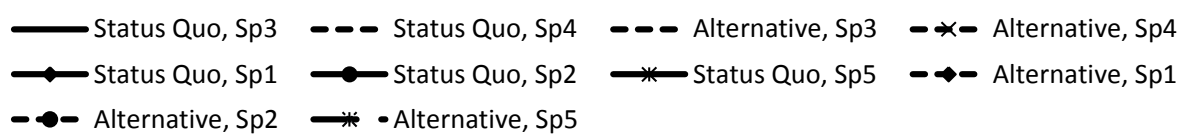

Figure 13 
Table 1. Basque Fleet Characteristics.

\begin{tabular}{|c|c|c|}
\hline Fleets & Trawlers & Purse seiner \\
\hline ICES sub-areas $^{\text {a }}$ & VI, VII and VIII $a, b, d$ & VIIIabce and Vll. \\
\hline Number of vessels ${ }^{\text {a }}$ & 34 & 58 \\
\hline Average length $(\mathrm{m})^{b}$ & 38 & 32 \\
\hline Average power $\left(\mathrm{kwh}^{\mathrm{b}}\right.$ & 461 & 467 \\
\hline Employment (people) $^{b}$ & $\begin{array}{c}420 \\
\text { (13 fishermen by vessel) }\end{array}$ & $\begin{array}{c}696 \\
\text { (12 fishermen by vessel) }\end{array}$ \\
\hline Main target species $^{\mathrm{a}}$ & Hake, anglerfish and megrim & $\begin{array}{c}\text { Mackerel, anchovy, bluefin tuna, } \\
\text { albacore, sardine }\end{array}$ \\
\hline Landing (tons) ${ }^{\mathbf{a}}$ & 9131 & 16600 \\
\hline $\begin{array}{l}\text { Annual revenue }(M €)^{a+b} \\
\text { (average of years } 2007: 2009)\end{array}$ & 39 & 29 \\
\hline
\end{tabular}

Source: ${ }^{\mathrm{a} L o g b o o k s}$ and sales notes; ${ }^{\mathrm{b}}$ Statistical information collected by the Basque Government through annual surveys of the fishing sector. Data of years 2007 - 2009. 
Table 2. Management measures and external factors matrix.

\begin{tabular}{|c|c|c|c|}
\hline \multicolumn{4}{|c|}{ Current and future management options } \\
\hline Purse seiners- BFT fishery & $\begin{array}{c}\text { External factor } 0 \\
E F O\end{array}$ & $\begin{array}{c}\text { External factor } 1 \\
E F 1\end{array}$ & $\begin{array}{c}\text { External factor } 2 \\
E F 2\end{array}$ \\
\hline \multicolumn{4}{|l|}{$\begin{array}{l}\text { Status quo } \\
\text { TAC system }\end{array}$} \\
\hline $\begin{array}{l}\text { Alternative } \\
\text { Introduction of IQ common pooling }\end{array}$ & $\begin{array}{l}\text { Temporary transferability } \\
\text { of the common pool } \\
\text { accompanied by a } \\
\text { reallocation of effort. }\end{array}$ & $\begin{array}{l}\text { Definitive transfer of the } \\
\text { quota accompanied by a } \\
\text { reallocation of effort. }\end{array}$ & \\
\hline \multicolumn{4}{|l|}{ Trawlers } \\
\hline $\begin{array}{l}\text { Status quo } \\
\text { TAC + transference-limited ITQ } \\
\text { system }\end{array}$ & Number of vessels & & \\
\hline $\begin{array}{l}\text { Alternative } \\
\text { Introduction of the LO policy }\end{array}$ & Number of vessels & $\begin{array}{l}\text { Elimination of scrapping } \\
\text { subsidies }\end{array}$ & $\begin{array}{l}\text { Increase of the TAC share } \\
\text { allocated to Spain - } \\
\text { indirect effects (imports) }\end{array}$ \\
\hline
\end{tabular}


Table 3: Rating results

\begin{tabular}{|c|c|c|c|c|c|c|c|c|c|c|c|c|c|c|}
\hline & \multicolumn{8}{|c|}{ BFT fishery } & \multicolumn{6}{|c|}{ Trawler fisheries } \\
\hline & \multicolumn{2}{|c|}{ STATUS QUO } & \multicolumn{2}{|c|}{ ALTERNATIVE } & \multicolumn{2}{|c|}{ E0 } & \multicolumn{2}{|c|}{ E1 } & \multicolumn{2}{|c|}{ STATUS QUO } & \multicolumn{2}{|c|}{ ALTERNATIVE } & \multicolumn{2}{|c|}{ E1 } \\
\hline & 15 & & 15 & & 15 & 25 & 15 & 25 & 15 & 25 & 15 & 25 & 15 & 25 \\
\hline \multicolumn{15}{|l|}{ EFFECTIVENESS } \\
\hline \multicolumn{15}{|l|}{ Environmental } \\
\hline TEI & $x$ & $x$ & $\sim$ & $x$ & $\sim$ & $x$ & $x$ & $x$ & & & & & & \\
\hline \multicolumn{15}{|l|}{ Economic } \\
\hline LEI profit/revenue & $\checkmark$ & $\checkmark$ & $x$ & $x$ & $\checkmark$ & $x$ & $x$ & $x$ & $x$ & $\checkmark$ & $x$ & $x$ & $x$ & $x$ \\
\hline TEI profit/revenue & $x$ & $x$ & $x$ & $x$ & $x$ & $x$ & $x$ & $x$ & $x$ & $\checkmark$ & $x$ & $x$ & $x$ & $x$ \\
\hline LEI RoFTA & $\checkmark$ & $\checkmark$ & $x$ & $x$ & $\checkmark$ & $x$ & $x$ & $x$ & & & & & & \\
\hline TEI RoFTA & $\mathbf{x}$ & $x$ & $x$ & $x$ & $x$ & $x$ & $x$ & $x$ & & & & & & \\
\hline \multicolumn{15}{|l|}{ Social } \\
\hline LEI & $\checkmark$ & $\checkmark$ & $\checkmark$ & $\checkmark$ & $\checkmark$ & $\checkmark$ & $\checkmark$ & $\checkmark$ & $\checkmark$ & $\checkmark$ & $\checkmark$ & $\checkmark$ & $\checkmark$ & $\checkmark$ \\
\hline TEI & $\sim$ & $\checkmark$ & $x$ & $\sim$ & $\sim$ & $\sim$ & $x$ & $\checkmark$ & $\checkmark$ & $\checkmark$ & $x$ & $x$ & $x$ & $x$ \\
\hline ACCEPTABILITY & $\checkmark$ & $\checkmark$ & $\checkmark$ & $\checkmark$ & $\checkmark$ & $\checkmark$ & $\checkmark$ & $\checkmark$ & $\checkmark$ & $\checkmark$ & $x$ & $x$ & $x$ & $x$ \\
\hline COHERENCE & $x$ & $x$ & $x$ & $x$ & $x$ & $x$ & $x$ & $x$ & & & & & & \\
\hline EFFICIENCY & & & & & & & & & $\checkmark$ & $\checkmark$ & $\checkmark$ & $\checkmark$ & $x$ & $x$ \\
\hline
\end{tabular}

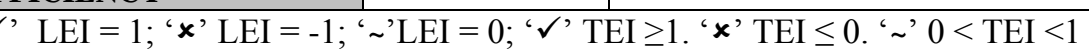

